\title{
The Importance of Lifelong Learning During and After COVID 19 Global Pandemic
}

\author{
Dama Mosweunyane (PhD) \\ University of Botswana, Department of Lifelong Learning and Community Development \\ Michael Manisa (MR) \\ University of Botswana, Department of Civil Engineering
}

\begin{abstract}
The importance of lifelong Learning during the outbreak of COVID 19, which originated from the Wahun in China, proved that it was important for people to continually learn. The pandemic changed the way how people conduct their lives because they have to keep themselves safe from getting infected by the fatal virus. It is important to note that the people who attach value on learning often continually inform themselves about the dangers that are imposed in their lives, such as in the event that a pandemic besiege their milieus in the manner that COVID 19 did. It is important to note that in Botswana the information about the pandemic and what the people needed to do to avoid getting infected was promulgated through various mediums, such as national television broadcasts, national and private radio stations and both government and private newspapers. It proved that the culture of learning is highly important when pandemics are experienced, because people who learn on a continuous basis often get important information timely about their lives, than those who are illiterate and attach little to no value on learning. The zeal to learn is highly beneficial as it makes the people to gather important information about their lives, which include learning about emerging infections such as COVID 19 and the impact that is normally occasioned by the outbreaks. The crucial point that is raised through this paper calls for governments, private sector and parastatals to expend resources for lifelong learning programmes, with much emphasis in the training of adults who are often not readily catered for, when having missed on the opportunities that are availed for the younger population in formal education. Lifelong learning programmes should be made to characterise communities at all costs through government and private sector spending, so that people can take learning as an investment that can save their lives, such as in the event that there is an outbreak. COVID 19 requires people to stay informed and the culture of learning to characterise their existence.
\end{abstract}

DOI: $10.7176 / \mathrm{JEP} / 11-36-17$

Publication date: December $31^{\text {st }} 2020$

\section{Introduction}

The world got besieged by a COVID 19 pandemic that disrupted human lives globally, leaving a trail of destruction with massive loss of human lives. As noted by Cennimo (2020), Coronavirus disease 2019 (COVID-19) is defined as illness caused by a novel coronavirus now called severe acute respiratory syndrome coronavirus 2 (SARS-CoV2; formerly called 2019-nCoV), which was first identified amid an outbreak of respiratory illness cases in Wuhan City, Hubei Province, China.

The virus claimed many lives including in developed countries such as the United States of America, Italy, Spain, China, leading to the World Health Organisation declaring it a pandemic.

It also negatively affected economies of both developed and developing countries with Botswana also suffering the effects of the pandemic. As noted by Centres for Disease Control and Prevention (2020) On March 11, 2020, the World Health Organization declared the COVID-19 outbreak a pandemic.

It is important to indicate that COVID 19 has caused massive devastation and disruptions globally. The virus is having social effects that brought about uncertainties amongst nations. The social effects have appeared in all nations because of the protocols that are necessitated to curb the spread of the virus. Social distancing, hygienic dictates such the frequent washing of hands have redefined the way how people relate and live, which has caused much anxiety. In the political front, the nations are faced with serious challenges of decision making, some of which are unpopular, such as restriction of movements of the people, which significantly affected the tourism industry globally. The use of technology has also posed a great challenge, as some rural areas are not ready to use modern technology for communication because of lack of gadgets, electrical power and expertise.

Most notably, the sharing of knowledge about the pandemic has become more significant and the change of behaviour of the people to become more responsive to the challenges brought about by the pandemic highly pivotal. What comes out as very important is the need for people especially those in the rural areas to continually learn, hence the need for lifelong learning opportunities. As defined by MEGEP, (2006) it is all learning activities undertaken throughout life with the aim of improving knowledge, skills and competences, within a personal, civic and social and/or employment-related perspective.

As noted by Maren (2020), educators around the world are alarmed about the consequences of the COVIID- 
19 crisis. A lively debate has emerged on what the world might look like in the aftermath of the crisis in relation to education.

This paper points out to the significance of lifelong learning during and post COVID 19 if the recovery process is to be achieved with less economic, social, political and environmental debilitating effects. It is worth noting that lifelong learning can serve as an important vehicle in the dissemination of information during and post COVID 19, in both developed and developing countries.

The role or lifelong Learning in the economic sphere

The economies of countries are experiencing challenges during the COVID 19 pandemic because the normalcy of operating businesses got disrupted as lockdowns and travelling restrictions had to be enforced to curb the spread of the virus. The pandemic has affected the formal and the informal sectors negatively, which calls for countries to provide knowledge to the citizenries about the negative effects the outbreak is having on the global economy and at the level of communities. As noted by (IMF, April 2020), Global economy is projected to decline by 3\%, which is far worse than a decline experienced in 2008 after the global financial crisis. This economic malady as explained by Gondwe (2020) is as a result of the fall in global demand for exports and a slump in prices of major commodities including fuels. There has also been a fall in Foreign Direct Investment (FDI), which is closely linked to the extractive sector and hence the commodity price cycle. Millard (2020) goes further to note that over the space of a few months, COVID-19 has triggered an economic contraction, leaving nearly half of the US population without a job. It is important to indicate that the US economy makes some significant contribution to the global economy, which means its contraction will have some significant negative effect on the global economic performance. As noted by UNRISD (2020) No doubt the financial losses caused by this crisis will further exacerbate inequalities, the concentration of wealth, economic and social precarity for the majority of people, and fiscal pressures on governments. Precarious

The prudent use of resources is highly pertinent than ever before if economies are to recover from the devastating effects of the pandemic within reasonable time. As noted by Gartner (2020), what makes the pandemic situation unique is that unlike other crises that have shorter or more predictable duration, this pandemic has an extended and uncertain duration. Rather than a traditional crisis strategy, enterprises must engage in nontraditional survival mechanisms associated with falling into a long economic trench.

The situation as it stands calls for countries to provide training in the use of technology to people, besides providing knowledge about COVID 19. Something that is also important is to equip people with knowledge on how the pandemic will affect the performance of global economies and what that means for their livelihoods. This dictates that resources be expended in the training of the people than for the leaders to take advantage of the situation and embark on self-enrichment undertakings, such as overpricing of commodities by the private sector.

It is evident that some people remain less informed about the pandemic and even where they are informed in some instances some unscrupulous entities and individuals deliberately take hyperbolical positions that get adopted to instil fear. Often this is meant to justify the actions of those who are economically manipulative, such as those who swindle state resources that could otherwise benefit the underprivileged.

There is also continued demand for formal education by the people because even in the middle of a pandemic, education should still be given to the people so that they ultimately become functional members of their respective nations. For example, the countries still should have engineers, social workers, medical doctors, nurses, economists and other professionals. This demand for education requires countries to inject more resources into the training of the people in an equitable manner and making sure that learning becomes a continuous process. For example, as noted by Schmidt (2000), lifelong learning is the basis of most undergraduate medical curricula, is central to the General Medical Council's document named, "Tomorrow's Doctors" and is a requirement, as part of continuing professional development, for all registered medical practitioners in the UK. It is important to note that lifelong learning even before COVID 19 pandemic, was pivotal for professional development. To attest to this proposition, Trotter (2006) notes that in education change is inevitable. Teachers are constantly learning, growing and adapting to new techniques, new content standards and new curricula. It is therefore crucial to note that during and after COVID 19, lifelong learning will even be more instrumental in making sure that professionals acquire new knowledge and skills. It is important to indicate that as professionals will be given knowledge and skills to function effectively during and post COVID 19, more resources will have to be made available by governments, NonGovernmental Organisations (NGOs) and the private sector.

The other area that needs attention is that of learning of the ordinary people who reside in the rural areas, without whose economic participation most countries will take forever to economically recover. The people in the rural areas who in most cases are denied resources, need to be catered for substantially through lifelong learning avenues so that they can restore their livelihoods. As averred by European Society for Education (2020), in the same way that economic recessions cause larger inequalities, today one of the most tangible results of the COVID 19 outbreak has been a wider gap between learners. Even in Europe, the wealthiest region in the world, there remain thousands of learners that are told to follow online courses but do not have the means to do so. 
It has to be admitted that some countries are not keen to invest in lifelong learning, which is a concept that is necessary to foster learning throughout the life of an individual. This anomaly is often attributed to lack of resources and yet it is more expensive to avoid massive costs that can be incurred in the event of a life threatening situation, such as in a case of a COVID 19.

It is therefore important to note that lifelong learning remains a vehicle that can enhance learning within the nations during and after COVID 19. As noted by OECD (2020), not a single day goes by that does not lead to the demand for additional skills, knowledge and/or competences for all individuals. For people outside the initial education and training system, adults in particular, it is very likely that this learning, taking place at home, at the workplace or elsewhere, is a lot more important, relevant and significant than the kind of learning that occurs in formal settings. In view of what OECD observed, it is important for countries in their efforts to combat the pandemic to make sure that learning takes place in different settings, and most importantly to make people attach value on learning. This requires the political will for governments to spend resources in developing the culture of learning through availability of valuable information about COVID 19 and other pertinent issues such as abject poverty.

It is indisputable that poor communities will have their socio-economic status further aggravated as a result of underperforming economies, most of which are in the African continent. As noted by Gondwe (2020) it is estimated that COVID 19 will drag African economies into a fall of about $1.4 \%$ in GDP, with smaller economies facing contraction of up to $7.8 \%$. The contraction is mainly as a result of export adjustments affecting primary commodity exporters, and the attendant losses to tax revenue, which reduce the capacity of governments to extend public services necessary to respond to the crisis. The economic crisis that will be experienced by countries as a result of COVID 19 requires parsimonious utilisation of resources, which should include channeling of such resources to the rural communities for their empowerment through knowledge provision. If countries are to realize economic prosperity they should provide knowledge and skills that are necessary for global economic recovery, such as entrepreneurial skills.

\section{The role of lifelong learning in the political sphere}

The role of lifelong learning in promoting decision making by communities is crucial if the countries are to avoid distress or any form of emotional capitulation amongst its populations. The decision making on matters concerning the pandemic and the training of ordinary people should not remain the purview of those in powerful positions. It should instead be an accommodative and participatory process that include the rural poor who in most instances are without prerequisite knowledge and skills for poverty alleviation. It is important to note that poor people are often not adequately catered for, so that they are knowledgeable and skilful. As observed by Elfert as cited by Stanistreet (2020), the current crisis need not result in a further erosion of social and economic rights and the widening of inequalities - it also represents an opportunity to appeal to global solidarity and rehumanize lifelong learning. In the current COVID-19 pandemic, the struggle to contain the outbreak and push back new infection figures will ultimately be won by training citizens on how to avoid creating secondary transmission chains.

The generation of apt decisions is necessary if the countries are to survive the pandemic and to revive their economies. As noted by Gartner (2020), decisions that executive teams would make during the normal course of business will differ sometimes aggressively from those they will make during the COVID-19 pandemic, due to crisis and disruption criteria: safety, continuity and resilience. The decision making process should be aligned to the provision of knowledge, skills and attitudinal changes, which should be re-directed at making nations more productive and responsive to vicissitudes brought about by the pandemic.

Lifelong learning must be utilized as it is the most appropriate in fulfilling the important undertaking of creating milieus where all stakeholders work together in the decision making processes. As observed by Higgs and Van Wyk (2009) learning is central to both economic and social cohesion, which suggests that lifelong learning cannot simply be driven by a need to secure economic prosperity but should also focus on the capacity of citizens to exercise and enforce democratic rights and participate effectively in decision making.

It is important to note that lifelong learning should provide some platform for people who are relegated into the periphery to exploit opportunities to make decisions and generate strategies for their amelioration during and after COVID 19. This calls for the necessary camaraderie of the private sector, civil society and public entities in fostering processes that are transformative. As averred by Abukari (2004), Lifelong Learning is viewed as involving all strategies that are put in place to create opportunities for people to learn throughout their lives. It should therefore be used with the understanding that it is a process of conscious continuous learning that goes throughout life and directed towards providing both the individual needs and that of the community.

It is important that countries embark on technological development to enhance the chances of regaining economic, political and social development. It therefore means that technology should receive resources, which requires the support of all stakeholders including governments, private sector and parastatals, so that people can be educated about the value of knowing, and also to provide avenues for research on COVID 19 topics. It is important to indicate that research will allow for more appropriate ways of dealing with the challenges brought 
about by the pandemic. This is because actions will be instigated from informed positions. As noted by UNRISD (2020) Research and scientific evidence also has a critical role to play in steering us through the crisis, guiding decision makers in uncertain times, and helping build better systems for the future.

The findings that are arrived at through research are important in any given country, as they can help in the development of better approaches in the education of the people on a continuous basis about changing global trends. This view is supported by Tindall (2005), who indicated that technology assisted Lifelong Learning aims to harness technology to support excellence in teaching, learning and research. Research and consultancy are undertaken on e-learning and technical projects, and high quality learning solutions are developed. Knowledge transfer challenges in teaching and learning, collaboration, dissemination of information can be promoted through the use of technology. It is important to note that lifelong learning is even necessary where those people who are technophobic will have to learn how to use available technological provisions if they are to remain relevant and operational.

As noted by Rasmussen and Jamieson (2020), we recognize that decisions made in the midst of a public health emergency are fraught with challenges and require careful consideration of the risks and benefits of various options. In the health sectors and departments of countries, as noted by Abrams, Shaker, Oppenheimer, et al (2020) shared decision making (SDM) is a management paradigm that empowers patients as partners in their own care in a bidirectional exchange of information and values, and optimization of the decision-making process. It is therefore important to ascertain that the people, mostly those in poor countries are provided with knowledge and skills not only for their survival, but also on how to deal with future health challenges.

During the current coronavirus disease 2019 pandemic, there is also a greater need to encourage participation in the SDM process and this calls for more information to be made available for consumption by countries. It is therefore appropriate that the area of research should be resourced, so that researchers can generate enough data, which is necessary to guide decision making by health practitioners, economists, educationists, politicians and other professionals.

Lifelong Learning stands to be the most apt vehicle by which information dissemination during and post COVID 19 can be achieved. It has to be noted that knowledge, skills and attitudinal change can be fostered through provision and utilization of the best facilities. As observed by China Research Yleimen (2016), the governments as well as private sector should provide good learning facilities and resources with the aim of promoting the comprehensive development of the citizens. These resources should encourage lifelong learning as a kind of independent and creative learning experience that helps learners survive in a rapidly changing society.

The countries in their fight against COVID 19 should utilize Lifelong Learning as a vehicle to instigate behavioral change of the citizenry. As noted by Baltaci (2020) in the current COVID-19 pandemic, the struggle to contain the outbreak and push back new infection figures will ultimately be won by training citizens on how to avoid creating secondary transmission chains. To demonstrate the value of knowledge provision, African Development Bank Group (2020) also averred that, empowering people with knowledge on how to avoid COVID19 is an investment and a high impact intervention. We need to educate people on the needs of distancing, masking up and ensuring that people are operating only in places where public health guidelines are observed.

\section{The role of Lifelong Learning in the social sphere}

The COVID 19 pandemic has left the countries in what has come to be referred to as, "the new normal", which means the cultures that had existed for centuries in some instances will have to change. The protocols for instance, dictates that some rituals that are performed during funerals in African societies are changed, as a large number of mourners cannot be allowed to attend a funeral at a time. The religious entities such as churches and mosques are also faced with a serious challenge of not allowing worshipers to congregate as they used to do before COVID 19. The restrictions that were brought about by COVID 19 have lessened the physical interactions of people within different geographical locations, which has an effect on how people communicate. The use of modern technology such as internet has taken precedence over traditional ways of communication, which leaves no hope that communities will ever revert to the primitive methods even post COVID 19. The situation will also be reinforced by the need by countries to gravitate towards fourth industrial revolution. As noted by World Economic Forum (2020 research suggests that online learning has been shown to increase retention of information, and take less time, meaning the changes coronavirus have caused might be here to stay.

It has to be noted that though use of technologies for communication is paramount the technological disparities that exist between rich and poor nations and between urban and rural areas should be bridged. The rural areas in most countries are lagging behind in development, with more resources get expended in urban areas where decisions are made for those in the periphery. Notably, this situation leaves many people without the necessary technologies for their development. It is also important to state that even before the global recession and COVID 19 pandemic besieged nations, the capitalist arrangement had produced inequalities among nations and societies. As observed by UNRISD (2020) The type of capitalism that we have allowed to take root in the past four decades has produced marked injustice in relation to the distribution of economic value - across countries, 
within societies, and inter-generationally. Rewards from private sector activity have trickled upwards to those who own or allocate capital, and away from workers who face increasingly precarious forms of employment. Also as suggested by Heijdra and Ter Weel (2019), labour market demand since the 1970s in particular is characterised by technological developments favouring high-skilled workers significantly over their lower-skilled peers. It is therefore important for governments and other stakeholders to allow lifelong learning to play its role of up-skilling those who are disadvantaged further by the outbreak of the pandemic.

As noted by Millard (2020) Sustainable Development Goals are failing in relation to key goals such as poverty eradication, economic equality, gender equality, and climate change. They need to be recalibrated in response to COVID-19 to be ready for the ensuing recession and accelerating global warming. Millard goes further to indicate that., poverty is a political choice and its elimination requires: (i) reconceiving the relationship between growth and poverty elimination; (ii) tackling inequality and embracing redistribution; (iii) promoting tax justice; (iv) implementing universal social protection; (v) centering the role of government; (vi) embracing participatory governance; and (vii) adapting international poverty measures. It is absolutely necessary for interventions to be employed as the world state of poverty will be aggravated by the pandemic, with telling effects on women. As noted by UN Women (2020), the pandemic will push 96 million people into extreme poverty by 2021, 47 million of whom are women and girls. This will bring the total number of women and girls living on USD 1.90 or less, to 435 million.

COVID 19 has negatively affected the performance of communities in the cultural front and performing arts, which will aggravate levels of poverty globally. As noted by Ramirez as cited in the UNESCO (2019), The COVID-19 pandemic has hit very hard the cultural sector. The majority of world heritage properties remain closed and many living heritage practices have had to be adapted or put on hold. The same aforementioned report by UNESCO states that $90 \%$ of the world museums had to close as the result of COVID-19. Maybe $30 \%$ may never reopen. As many festivals and cultural events were cancelled, artists and cultural professionals are struggling to make ends meet.

It is clear that social development will be compromised in countries that are still developing most of which are in Africa, Asia and Latin America. It is so because resources that are supposed to be expended in development will instead be used in fighting COVID 19. The other problem is that due to uncertainties surrounding social and economic performance of countries, corruption characterised by over pricing of goods and services for the governments and the private sector by unscrupulous businessmen/women will escalate. As noted by New Nouveau Brunswick (2009), social development means investing in people. It requires the removal of barriers so that all citizens can journey toward their dreams with confidence and dignity. It is about refusing to accept that people who live in poverty will always be poor. It is about helping people so they can move forward on their path to selfsufficiency. It is also making sure that as knowledge change people are accorded the necessary opportunities to learn new things. As pointed out by Jarvis (2004), knowledge changes rapidly and consequently the so called "front end" model of education, which was appropriate for less technological societies, is no longer relevant to contemporary societies.

It is very important to indicate that Lifelong Learning is important in the realisation of social development because as averred by New Nouveau Brunswick (2009), learning must start early in life. By investing in early learning initiatives we can ensure a greater degree of success amongst our citizens. Making sure that children get a good start in their education goes a long way to increase their success later in life.

It is important for countries to find more viable ways by which the social undertakings will be used to enhance economic recovery, such as through cultural festivals and performing arts. It is important to note that culture is very important in development, as it will be in the recovery programmes of countries post COVID 19. As pointed out by Ontario (2019), a growing body of research also demonstrates that the arts can improve the health and wellbeing of older adults. Participation in the arts can relieve isolation and promote identity formation and intercultural understanding. It is important for countries to ascertain that in their recovery strategies post COVID 19, culture is given priority for its health benefits, which are said to be even more crucial for older adults who in most African countries still hold tenaciously to their cultural facets including the arts.

UNESCO (2019) provides a solution that comes handy in the recovery process, which is that we must rethink development strategies taking into account the pressing issues this crisis has highlighted namely: inequality and unsustainable growth, but also the related challenges of governance, climate change and the opportunity of the fourth industrial revolution.

It is evidently clear that culture will play some pivotal role in uniting communities following COVID 19, which through its protocols has placed them apart because of movement restrictions. As noted by Ontario (2019) culture helps build social capital, the glue that holds communities together. By bringing people together, cultural activities such as festivals, fairs, or classes create social solidarity and cohesion, fostering social inclusion, community empowerment, and capacity-building, and enhancing confidence, civic pride and tolerance. The social capital created through culture increases with regular participation in cultural activities. Cultural engagement also plays a key role in poverty reduction and communities-at-risk strategies. As noted also by Ministry of Tourism, 
Culture and Sports (2016), the role of culture in strengthening communities is increasingly being recognized. Many strategies incorporate culture into community planning to enrich quality of life for residents, create a unique sense of place, and reap economic benefits through revitalized neighbourhoods and cultural tourism. The other important point that can add value on the recovery plan post COVID 19 is advanced by UNRISD (2020) who indicated that, it is essential to rethink policy priorities, fundamental societal values, and strategic development directions for the coming decade of action. Strong, solidarity-based alliances between people, collective action and unwavering pressure will be essential to achieve a vision of social justice, equality and sustainability.

\section{Conclusion}

This paper clearly observed that the COVID 19 pandemic placed countries in a situation characterized by negative economic, political and social effects that will take time to be overcome. It also emerged any recovery will chiefly depend on the effectiveness of the strategies that countries will employ. The recovery process can be effective through the utilization of the lifelong learning programmes to promote learning about the pandemic and economic and social recovery strategies.

The global economy has experienced some slump, which requires some participation of the people, including those that are currently relegated to the periphery and notably economically disadvantaged. The pandemic is likely to further plunge the already poor people who lead wretched lives into further economic misery, which will inevitably reduce their political activity or decision making capacity. Their political passiveness will translate in them not making decisions that are necessary for their amelioration.

The governments should invest their resources in the economic, political and social developments of their countries, which will speed the recovery process of even the Third World countries, which were already struggling to emerge from effects of economic global recession.

This paper has successfully demonstrated that through lifelong learning, which advocates for the learning process to commence from birth to death, knowledge and skills can be passed on for the political and social advancement of the people. Lifelong Learning is demonstrated that it can be instrumental in the uplifting people from doldrums of human deprivation. The problems associated with ignorance can also be overcome through lifelong learning avenues that which governments should invest on.

\section{References}

Abrams, E.M. Shaker, M. Oppenheimer, J. Davis, R.S. Bukstein, D.A. and Greenhawt, M. (2020) The challenges and opportunities for shared decision making highlighted by COVID 19. Rockville, MD: US Department of Health and Human Services.

Abukari, A. (2004).Conceptualising Lifelong Learning: A Reflection on Lifelong Learning. (pp.1-21), 1st International euredocs conference sciences: Transformations experienced by higher education and research institutions in European countries. Paris. Retrieved from: euredocs.sciencespo.fr/en/conference/2004/abdulai abukari.pdf. on the ( $1^{\text {st }}$ October, 2020).

African Development Bank Group (2020) The importance of African civil society for building post-COVID 19 resilience. Retrieved from: AFDB.org (Retrieved on the 09/10/2020).

Baltaci, S. (2020) Adult learning and education as a tool to contain pandemics: The COVID 19 experience. European Commission. Available on http://link.springer.com/article/101007/s11159020-09843-0 (Retrieved on the $08 / 10 / 2020$ ).

Cennimo, D. (2020). What is COVID 19? New Jersey: Rutgers New Jersey Medical School.

Centres for Diseases Control and Prevention (2020). Severe outcomes among patients with Coronavirus Disease 2019 (COVID 19) - United States, February, 12- March, 16, 2020. Morbidity and Mortality Weekly Report. Vol. 69, pp.1-4.

China Research Yleimen (2016). The essential characteristics of Lifelong Learning. Globaleducation.

European Civil Society for Education (2020). Lifelong Learning Platform COVID 19 statement. Brussels: Available: info@lllplatform.eu (Retrieved on the 09/09/2020).

Gondwe, G. (2020). Assessing the impact of COVID-19 on Africa's Economic Development. New York: United Nations UNCTAD.

Government of Ontario (2019) The importance of Culture. Ontario: Queen's Printer for Ontario.

Heijdra, B. J. and Ter Weel, B. (2019). Jan Tinbergen: Engineering a better world. De Economist, 167 (3), pp.215-219. Retrieved from https://doi.org/[10.1007/s10645-019-09348-8 (Retrieved on the 20/10/2020).

Higgs, P. and Van Wyk, B. (2009) Lifelong Learning revisited: an African educational discourses. London: Taylor \& Francis Group.

IMF (April, 2020). World Economic Outlook Update. Available: www.imf.org. (Retrieved 09/09/2020).

Jarvis, P. (2004) Adult education and Lifelong Learning. London: Taylor and Francis Group.

Maren, E. (2020). COVID-19: Rehumanizing education and Lifelong Learning. UNESCO: Shutterstock. 
MEGEP (October, 2006). Driving Force for the Success of Turkey. Lifelong Learning Policy Paper. Ankara: Government of Turkey.

Millard, J. (2020) impacts of COVID-19 on social development and implications for the just transition to sustainable development. Retrieved from: https://gdpr.eu. (Retrieved on the 10/10/2020).

Ministry of Tourism, Culture and Sports (2016) Environmental scan of the culture sector: Ontario culture strategy background document. Ontario: Communications MDR.

New Nouveau Brunswick (2009) What is Social development? Brunswick: Economic and Social Inclusion Corporation.

OECD (2020) Recognition of Non-formal and Informal learning. Available on: OECD.org (Retrieved on 18/09/2020).

Ramirez, E.O. (2019) SDGs and Sustainable Social Development: An effective recovery from COVID 19. Retrieved from: www.UNESCO.org (Retrieved on the 10/10/2020).

Rasmussen, S.A. and Jamieson, D.J. (2020) Public health decision making during COVID 19-Fulfilling the CDC pledge to the American people. Massachusetts: NEJM Group.

Stanistreet, P. (2020). COVID 19: Rehumanising education and Lifelong Learning. Hamburg: UNESCO Institute for Lifelong Learning. Hewlett-Packard CompanyHewlett-Packard Companyjm.

Tindall, S. (2005). Technology-Assisted Lifelong Learning, Department for Continuing Education. University of Oxford: Available: uk.linkedin.com/pub/sara-tindall/a/73a/a86./ (Retrieved on the $1^{\text {st }}$ October, 2020).

Trotter, Y.D. (2006). Adult Learning theories: Impacting professional development programs. International Journal for Professional Educators. Austin: Delta Kappa Gamma Society International.

UN Women (2020) COVID 19 and its economic toll on women: The story behind the numbers. New York: United Nations Secretariat.

UNESCO (2019) SDGs and Sustainable Social Development: An effective recovery from COVID 19. Retrieved from: www.UNESCO.org (Retrieved on the 10/10/2020).

UNRISD (2020) How social development steps up to the plate in times of crisis: Learning from the past, surviving the pandemic, creating sustainable futures. Geneva: Palais des Nations.

World Economic forum (2020) The COVID 19 pandemic has changed education forever. This is how. Retrieved from weforum. Org/agenda/2020/04/coronavirus-education-global-covid19-online-digital-learning/ (Retrieved on the 27/10/2020). 